\title{
EFEITO DO ESTRESSE OSMÓTICO SOBRE A PRODUÇÃO DE ANTOCIANINA EM CALOS DE Byrsonima gardneriana A. JUSS.
}

\author{
Thais Akemi Ogasawara da Silva ${ }^{1}$, Lenaldo Muniz de Oliveira ${ }^{2}$ \\ Katiane Oliveira Porto ${ }^{3}$
}

1. Bolsista PIBIC/CNPq, Graduando em Agronomia, Universidade Estadual de Feira de Santana, e-mail: akemithais@ @otmail.com

2. Orientador, Departamento de Biologia, Universidade Estadual de Feira de Santana, email: lenaldo.uefs@gmail.com

3. Mestranda do PPGRGV/UEFS, e-mail: ksoliveira07@gmail.com

PALAVRAS-CHAVE: Malpighiaceae, Cultivo in vitro, Compostos fenólicos

\section{INTRODUÇÃO}

O gênero Byrsonima é o maior da família Malpighiaceae e agrupa espécies de grande importância medicinal, ornamental e produtoras de frutos comestíveis (RIBEIRO et al., 1999), sendo conhecidas popularmente como "murici. Entre as espécies deste gênero está a Byrsonima gardneriana A. Juss. que é nativa e endêmica do Brasil, sendo distribuída nos domínios fitogeográficos da Amazônia, Caatinga, Cerrado e Mata Atlântica (MAMEDE, 2015). Relatos da literatura reportam atividade antioxidante do extrato etanólico bruto da espécie a qual é justificada pela presença de flavonoides (MENDES et al., 1999).

Os flavonoides compõem a maior classe de compostos fenólicos e compreendem um grande numero de substâncias coloridas, como as antocianinas, responsáveis pela maioria das cores vermelha, rosa, roxa e azul percebidas nos vegetais (TAIZ \& ZEIGER, 2006). As antocianinas apresentam ampla utilização na indústria, com destaque na farmacêutica, cosmética e alimentícia (CARDOSO et al., 2011).

Uma alternativa viável para a produção de metabolitos secundários de interesse, como as antocianinas, é o cultivo in vitro de células e tecidos vegetais, em virtude das vantagens desse sistema de cultivo. Nesse contexto, o cultivo de calos tem sido considerado a alternativa mais apropriada para a produção de compostos secundários de interesse, a exemplo das antocianinas (AMMIRATO et. al., 1984). Uma alternativa para estimular a maior produção de compostos secundários, normalmente presentes em baixa concentração nos tecidos, é a indução de estresse osmótico (Rajendran et al (1992).

Com base nos aspectos apresentados, o objetivo desse trabalho foi avaliar o efeito do estresse osmótico sobre a produção de antocianinas em calos de Byrsonima gardneriana A. Juss.

\section{MATERIAL E MÉTODOS}

Os frutos de B. gardneriana tiveram seus endocarpos abertos para a retirada das sementes, as quais foram desinfestadas em câmara de fluxo laminar através da imersão em álcool $70 \%$ por 30 segundos, seguido de hipoclorito de sódio a 1\% acrescido de uma gota de detergente neutro por 10 minutos. Posteriormente, as mesmas foram inoculadas em tubos de ensaio contendo $10 \mathrm{~mL}$ de meio de cultura MS (MURASHIGE; SKOOG, 1969) com metade das concentrações salinas (MS/2), suplementado com 3\% de sacarose e solidificado com 0,7\% de ágar. $\mathrm{O}$ pH do meio foi ajustado para 5,7 $\pm 0,1$ antes da autoclavagem. Após as inoculações os tubos foram fechados com filme PVC e as culturas foram mantidas em sala de crescimento com temperatura de $25 \pm 3^{\circ} \mathrm{C}$, fotoperíodo de 16 horas, umidade relativa de $60 \%$ e radiação fotossintética ativa de $40 \mu \mathrm{mol} \mathrm{m} \mathrm{m}^{-2} \mathrm{~s}^{-1}$. 
Segmentos de folhas com aproximadamente $0,5 \mathrm{~cm}^{2}$ foram obtidos após 60 dias de cultivo, para servirem como explantes. Estes foram inoculados em meio de cultura MS suplementado com 3\% de sacarose e solidificado com $0,7 \%$ de Agar e, para a indução dos calos, o meio foi suplementado com $16 \mu \mathrm{M}$ de BAP $+2 \mu \mathrm{M}$ de ANA. $\mathrm{O}$ pH do meio de cultura foi ajustado para $5,7 \pm 0,1$ antes da autoclavagem à temperatura de $121^{\circ} \mathrm{C}$ por 15 minutos. Os explantes foram inoculados em tubos de ensaio contendo $15 \mathrm{~mL}$ de meio de cultura, sendo mantidas em sala de crescimento, na ausência de luz por 30 dias pra indução dos calos.

Para indução do estresse osmótico amostras de calos foram transferidas para o mesmo meio de cultura original, de indução dos calos, acrescido de diferentes concentrações de sacarose e manitol: $30.0+0.0$ (controle); $30.0+2.5 ; 30.0+5.0 ; 30.0+7.5$ e $30.0+10.0 \mathrm{~g} \mathrm{~L}^{-}$ 1 , respectivamente. Decorridos 30 dias nesse meio as amostras de calos foram coletadas para quantificação da massa fresca e do teor de antocianinas, utilizando-se três repetições com três amostras (3 tubos) em cada repetição.

A extração das antocianinas foi realizada de acordo com Silva (1996), descrito por Teixeira et al. (2008). As amostras de calos foram previamente pesadas e trituradas, a qual foram adicionados $80 \mathrm{~mL}$ de Solvente extrator (Etanol-Água (70:30)) e $\mathrm{HCl}$ suficiente para ajustar o pH do meio para 2,0. O material, então, foi deixado em repouso por 24 horas a $5^{\circ} \mathrm{C}$, ao abrigo da luz. Findado o período o material foi prensado em filtro de tecido e o extrato transferido para balão volumétrico de $100 \mathrm{~mL}$, tendo seu volume completado com o solvente extrator. O conteúdo do balão foi centrifugado a $2000 \mathrm{rpm}$ por 10 minutos. O sobrenadante foi filtrado e o extrato purificado, extraindo-se (três extrações sucessivas) o conteúdo de clorofila com auxílio de 10mL de solvente extrator Éter Etílico: Éter de petróleo (1/1). O teor de antocianina foi avaliado em espectrofotômetro UV/VIS, efetuando-se leituras em comprimento de onda de $535 \mathrm{~nm}$. O conteúdo total de antocianinas foi expresso em $\mathrm{mg}$ de antocianinas $/ 100 \mathrm{~g}$ da fração da amostra analisada.

\section{RESULTADOS E DISCUSSÃO}

Durante o estabelecimento in vitro da espécie verificou-se baixa taxa de contaminação (2\%), demonstrando eficiência do protocolo de desinfestação, porém, a taxa de germinação foi de apenas 40,6\% decorridos 30 dias da inoculação das sementes. Este fato, provavelmente, ocorreu em virtude da baixa viabilidade do lote de sementes utilizado ou devido à dormência nas sementes, comum em espécies do gênero, como mencionado por Lorenzi (2002) apud Nogueira et al. (2004).

Os segmentos foliares apresentaram, após 30 dias da inoculação na ausência de luz, todo explante recoberto por calo, sendo estes de coloração amarela com regiões rosadas e textura compacta. A formação de calos com a utilização dos reguladores BAP e ANA também foi reportada por Pereira et al. (2012), que relataram a eficiência da utilização desses reguladores sobre a formação de calos em explantes foliares de Hyptis leucocephala.

$\mathrm{O}$ efeito do estresse osmótico sobre a produção de antocianinas foi distinta entre os tratamentos, sendo dependente das concentrações de manitol utilizadas. Em concentrações menores de manitol (até $5 \mathrm{~g} \mathrm{~L}^{-1}$ ) houve um aumento significativo na concentração de antocianinas nos calos, já em concentrações maiores do agente osmótico $\left(7,5 \mathrm{~g} \mathrm{~L}^{-1}\right.$ e $\left.10 \mathrm{~g} \mathrm{~L}^{-1}\right)$ verificou-se uma redução significativa no teor do pigmento (Figura 1). Assim, infere-se que nessas concentrações o estresse afetou o metabolismo das células, resultando na diminuição das antocianinas. Resultados semelhantes foram descritos por Suzuki (1995) ao testar as concentrações de 0,6 e 0,7 M de D-manitol em Vitis hybrids. 


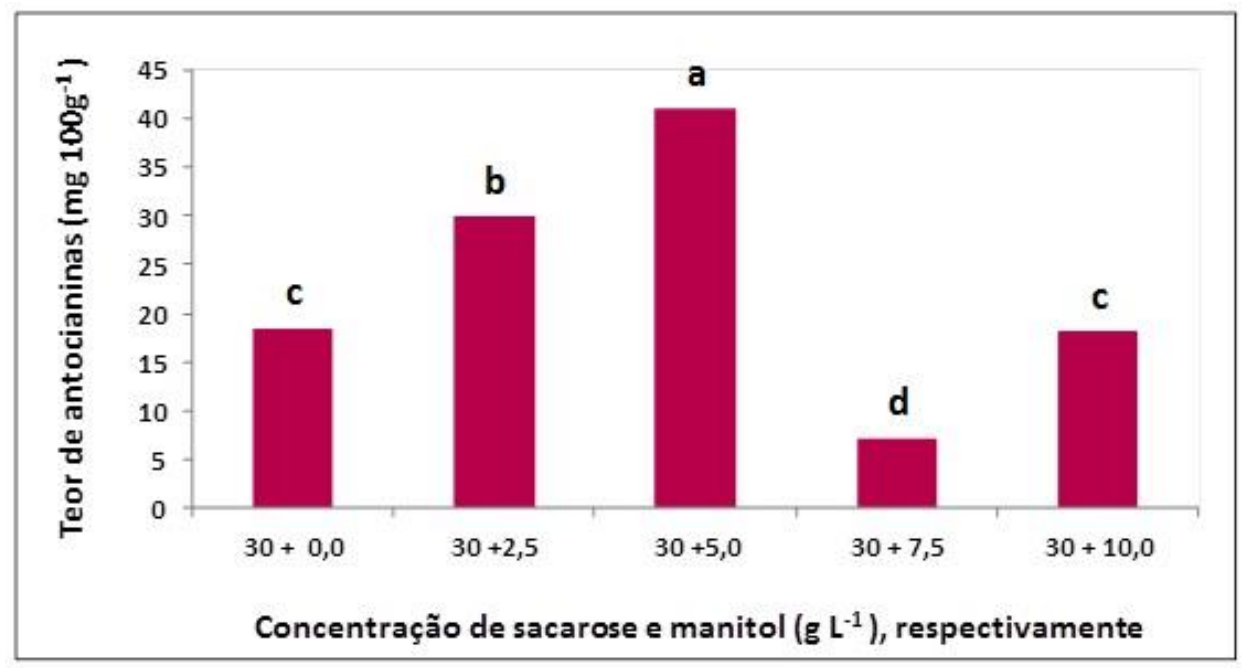

Figura 1: Produção de antocianinas em calos de Byrsonima gardneriana A. Juss cultivados em meio MS suplementado com diferentes combinações de sacarose e manitol por 30 dias. Médias seguidas pela mesma letra não diferem significativamente pelo teste de KruskalWallis a 5\% de probabilidade. Feira de Santana, 2017.

De modo geral, os calos submetidos ao tratamento osmótico apresentaram cores mais rosadas em relação ao controle, sugerindo maior produção de antocianinas, embora estes também tenham apresentado maior proporção de tecidos oxidados. Apesar da possibilidade de observação das antocianinas a olho nu, em virtude da coloração rosada dos calos, os calos que apresentaram maior teor de antocianinas (submetidos a $5 \mathrm{~g} \mathrm{~L}^{-1}$ de manitol) pouco se diferenciaram dos calos submetidos ao tratamento com $7,5 \mathrm{~g} \mathrm{~L}^{-1}$ de manitol, os quais apresentaram menor teor de antocianinas, indicando a pouca correspondência entre cor e teor de antocianinas em calos. Ressalta-se que o processo de oxidação dos calos dificulta a identificação visual, daí inferir-se que este método não seja adequado para uma possível seleção dos calos.

Os resultados obtidos demonstraram que os diferentes tratamentos de estresse osmótico não afetaram a massa fresca dos calos. Rajendran et al. (1992) sugerem que o estresse osmótico induz a mobilização de precursores do metabolismo primário para o metabolismo secundário, ou seja, o redirecionamento da rota metabólica do crescimento para a produção de compostos de defesa contra o estresse. Agentes osmóticos, como a sacarose e o manitol, reduzem o potencial hídrico do meio de cultura (CALDAS et al., 1998; ENGELMANN, 1991; LÉDO et al., 2007) apud (BRITO et al., 2011) e por consequência provoca o estresse oxidativo (Rossi et al., 2012). Como resposta a isso, além da síntese de metabolitos para o ajuste osmótico também são sintetizados compostos como as antocianinas, que atuam como antioxidantes endógenos (Malacrida \& Motta, 2006).

\section{CONCLUSÕES}

É possível a produção de antocianinas a partir de calos da espécie Byrsonima gardneriana A. Juss. O estresse osmótico moderado pode ser uma ferramenta para estimular o aumento no teor de antocianinas em calos da espécie, aumentando a eficiência de produção da mesma. Novos trabalhos devem ser realizados buscando otimizar o meio e as condições de cultura para maior produção desse pigmento.

\section{REFERÊNCIAS}

BRITO, A. B.; ALBUQUERQUE, M. M. S.; ALVIM, B. F.M.; RESENDE, S. V.; BELLINTANI, M. C.; SANTANA, J. R. F. Agentes osmóticos e temperatura na conservação in vitro de sempre-viva. Ciência Rural, Santa Maria, v.41, n.8, p.1354-1361, ago, 2011. 
MALACRIDA, C. R.; MOTTA, S. Antocianinas em suco de uva: composição e estabilidade. Boletim do Centro de Pesquisa de Processamento de Alimentos, Curitiba, v. 24, n. 1, p. 5982, jan./jun. 2006.

NOGUEIRA, R. C.; PAIVA, R.; CASTRO, A. H.; VIEIRA, V. C.; ABBADE, L. C.; ALVARENGA, A. A. Germinação in vitro de murici-pequeno (Byrsonima intermedia A. Juss.). Ciênc. agrotec., Lavras, v. 28, n. 5, p. 1053-1059, set.out., 2004

PEREIRA, D. M. S.; OLIVEIRA, L. M.; NEPOMUCENO, C. F.; SANTANA, J. R. F.; SILVA, M. L. C.; KOBLITZ, M. G. B. Indução e caracterização morfológica e bioquímica de calos de Hyptis leucocephala (Lamiaceae). Sitientibus série Ciências Biológicas 12(1): 151156. 2012.

PIASSI, M.; PIASSI, M. Otimização de protocolo para indução da calogênese in vitro em folhas cotiledonares de alface (Lactuca sativa L.). Revista Científica Intelletto Espirito Santo. p.135-142. v.2, n.2, 2016

PORTO, K. O.; OLIVEIRA, L. M.; LUCCHESE, A. M.; Produção de antocianinas em calos de Martianthus leucocephalus (Mart. ex Benth.) J.F.B. Pastore em resposta ao tempo de cultivo, à luz e ao estresse osmótico. Artigo (Especialização) - Universidade Estadual de Feira de Santana. Bahia. 2016.

RAJENDRAN, L.; RAVISHANKAR, G. A.; VENKATARAMAN, L. V.; PRATHIBA, K. R.; anthocyanin production in callus cultures of daucus carota as influenced by nutrient stress and osmoticum. Biotechnology Letters v. 14 No.8 (august 1992) pp.707-712.

ROSSI, V. S. Mecanismo antioxidante em plantas. 10 ${ }^{\circ}$ mostra acadêmica UNIMEP. 2012.

SCOTT, L. C. Environmental Significance of Anthocyanins in Plant Stress Responses. Photochemistry and Photobiology, 1999, 70: 1-9.

SUZUKI, M. Enhancement of Anthocyanin Accumulation by High Osmotic Stress and Low pH in Grape Cells (Vitis hybrids). Plant Physiol. Vol. 147. pp. 152-155(1995).

TAIZ, L.; ZEIGER, E. Fisiologia do estresse. In:Fisiologia vegetal. Trad. SANTARÉM et al. São Paulo: Artmed, p.613-641, 2006. 